Original Article

\title{
OPTIMIZATION AND CHARECTERIZATION OFINTRACELLULAR ORANGE FLUORESCENT PIGMENT FROM BACILLUS ENDOPHYTICUS (AVP-9(Kf527823)
}

\author{
MANTRI SAI RAM" ${ }^{1}$ NOKKU PRADEEP KUMAR², C. V. S. BHASKAR ${ }^{3}$. AMRUTHA V. AUDIPUDI* ${ }^{*}$ \\ ${ }^{1,2,4}$ Department of Microbiology, Acharya Nagarjuna University, Guntur 522510, A. P. India, ${ }^{3}$ Department of Botany. V. R College, Nellore \\ 523001, A. P, India \\ Email: audipudi_amrita@yahoo.com
}

Received: 20 May 2017, Revised and Accepted: 22 Jul 2017

\begin{abstract}
Objective: Our study aimed to characterize and optimize the physico-chemical properties which render the high yield of intracellular orange fluorescent pigment (IOFP) and its antibacterial activity against clinical pathogens.

Methods: Intracellular orange fluorescent pigment (IOFP) extracted from Bacillus endophyticus AVP-9(Kf527823) a rhizobacteria of chilli agricultural field using different solvent systems, fractioned by TLC and analyzed for absorption maxima. Purified pigment was screened for antimicrobial activity against clinical pathogen, Optimization of cultural conditions for maximizing the yield of pigment and compared the yield in different broth media.

Results: AVP-9(Kf527823) showed circular, large orange color colonies which fluoresced orange under U. V light,. Intracellular pigment affectively extracted in acetone showed a bright fluorescent orange spot on the TLC plate, and absorption maxima at $493 \mathrm{~nm}$. Antibacterial activity of isolated pigment showed highest zone of inhibition against E. coli and least to Pseudomonas. Maximum yield of the pigment was achieved in modified nutrient brot $(\mathrm{MNB}) \mathrm{h}$ medium containing $2 \% \mathrm{w} / \mathrm{v}$ nutrient broth containing $1 \% \mathrm{w} / \mathrm{v}$ glucose, $1 \% \mathrm{w} / \mathrm{v}$ peptone and $0.5 \%$ methionine at $35{ }^{\circ} \mathrm{C}$ and $\mathrm{pH}$ 7.0 with $48 \mathrm{~h}$ of incubation period. The yield was observed maximum in MNB. Compared to lactose broth, Tryptone soya broth and peptone water.
\end{abstract}

Conclusion: Bright fluorescent orange pigment of Bacterium avp-9(Kf527823) with absorption maxima at 493 indicating that the pigment shows the characters of carotenoids. Yield maximum in MNB and its potential antibacterial activity needs further investigation for pharmaceutical applications.

Keywords: Fluorescent pigment, Anti bacterial activity, Optimization, Morphological

(C) 2017 The Authors. Published by Innovare Academic Sciences Pvt Ltd. This is an open access article under the CC BY license (http://creativecommons.org/licenses/by/4.0/] DOI: http://dx.doi.org/10.22159/ijcpr.2017v9i5.22142

\section{INTRODUCTION}

Soil microbial communities are the most complex, diverse and important assemblages of organisms in the biosphere and they are an important source for the search of novel antimicrobial agents and molecules with biotechnological importance such as microbial pigments that can be used as natural colorants as well as antimicrobial agents in place of antibiotics [1]. The demand for new antibiotics continues to rise due to the rapid emergence of antibiotic resistant pathogens causing life threatening infections in spite of considerable progress in the fields of chemical synthesis and engineered biosynthesis of antimicrobial compounds [2]. This changing pattern of diseases and the emergence of resistant bacterial strains to currently used antibiotics continuously put demand on the drug discovery scientists to search for novel antibiotics such as microbial pigments [3]. Pigments of various colors are synthesized to protect the cells of micro-organisms from the injurious effect of light rays of visible and near ultraviolet range [4]. These pigments are synthesized by various types of microorganisms as secondary metabolites and not often found in all types of organisms [5-6]. Microorganisms produce various pigments like carotenoids, melanins, flavins, quinones, prodigious and more specifically mole-skin, violacein or indigo [7]. Carotenoid is an organic pigment that is noted in most of the plants and microorganisms which are essential to plants for photosynthesis, and protection against destructive photo oxidation [8].

Carotenoids are generally not manufactured by the animal, although one species of aphid is known to have acquired the genes for carotenoid synthesis from fungi, by mechanism of horizontal gene transfer. Human beings are unable to synthesize carotenoid and must obtain through diet. There are over 600 known carotenoid and is split into two classes as hydrocarbon carotenes (alpha-carotene, beta-carotene and lycopene) and Xanthophylls (lutein, astaxanthin, canthaxanthin and zeaxanthin). Carotenoid are highly colored (red, orange and yellow) and their color is directly related to their structure. Carotenoid plays an important role in human health. Numerous dietary studies have shown that carotenoid combat various types of cancers, macular eye diseases and cardiovascular problem and other diseases because of provitamin a function [9]. Carotenoids are potent biological antioxidants that can absorb the excited energy of singlet oxygen onto the carotenoid chain leading to the degradation of the carotenoid molecules but preventing other molecules or tissues from being damaged [10]. Fluorescent pigmented bacterium belongs to genus bacillus are gram positive rod shaped bacteria able to grow on one-carbon compounds (e. g. glucose) as well as on a wide range of cultivation substrates as sole source of carbon and energy [11]. Their distinctive pigmentation is due to carotenoids, which render them to be tolerant to extreme light condition and radiation. In recent years, due to their different applications in the fields of industrial, agriculture, and bioremediation, these florescent pigments attracted much attention. Inspired by these facts, the aim of this research was to characterize and optimize the physico chemical properties to attain high production of fluorescent pigment from avp-9(Kf527823) and evaluate the antimicrobial activity against human pathogenic bacteria.

\section{MATERIALS AND METHODS}

\section{Characterization of AVP9}

The Bacillus endophyticus AVP-9((Kf527823) was isolated from agricultural field of Guntur district, A. P India. Colony morphology, biochemical and physiological characterization aid in identifying and classifying organism into taxonomic groups were evaluated [12].

\section{Extraction of intracellular orange fluorescent pigment (IOFP)}

A $1000 \mathrm{ml}$ of conical flasks containing $500 \mathrm{ml}$ of nutrient broth $(\mathrm{g} / \mathrm{l})$ was prepared and used, $24 \mathrm{~h}$ old inoculum (1\%) was in addition to the flasks and incubated at $37^{\circ} \mathrm{C}$ in a sterile condition to $48 \mathrm{~h}$. After 
$48 \mathrm{~h}$ of incubation, the medium was centrifuged at $10,000 \mathrm{x}$ for 10 min at $4{ }^{\circ} \mathrm{C}$. Pigment was extracted from cell pellets by shaking with different solvents, and it was sonicated. Debris was removed by centrifugation at $10,000 \mathrm{x}$ g for $20 \mathrm{~min}$ at $4^{\circ} \mathrm{C}$. The solvent extracts of the pigment was evaporated at room temperature and it was dissolved in approximately $1 \mathrm{ml}$ of solvents and transferred into fresh sterile micro tubes. It was again evaporated at room temperature to concentrate the pigment.

\section{Thin layer chromatography and spectrophotometry}

Fractionation of Crude Pigment by thin layer chromatography with acetone was done using silica gel GF254 as absorbent and solvent system chloroform: ethyl acetate (3:1). Cell pellet was dissolved in $1 \mathrm{ml}$ of acetone and centrifuged (10000g) and absorption spectrum of the acetone extract was recorded at $\lambda 350$ to $\lambda 800$ in spectrophotometer [13].

\section{Optimization of growth and pigment production}

Optimization for the production of fluorescent pigment from AVP-9 (Kf527823) was made with nutrient broth. One fifty ml conical flask containing $50 \mathrm{ml}$ of nutrient broth $(\mathrm{g} / \mathrm{l})$ was prepared and sterilized separately. $48 \mathrm{~h}$ old inoculum (1\%) was added to each of the flasks and incubated at $37^{\circ} \mathrm{C}$ in a sterile condition. After $48 \mathrm{~h}$ of incubation period, broth was taken for pigment extraction [14-17]. Effect of temperature was carried out at $4{ }^{\circ} \mathrm{C}, 15^{\circ} \mathrm{C}, 25^{\circ} \mathrm{C}, 30^{\circ} \mathrm{C}, 35^{\circ} \mathrm{C}, 37^{\circ} \mathrm{C}$ and $40{ }^{\circ} \mathrm{C}$ keeping all other conditions at their standard levels. Optimum incubation period for the production of fluorescent pigment was set out at $16 \mathrm{~h}, 24 \mathrm{~h}, 36,48,60$ and 72 , at $12 \mathrm{~h}$ interval. The effect of inoculum size on growth and pigment production was determined by taking different cell concentrations $[0.5,1.0$ and $1.5 \%)$ different flasks. The selected strain was inoculated in nutrient broth having different $\mathrm{pH}$ such as $3,4,6,7,8$, 9and10. Growth and pigment production was measured at $450 \mathrm{~nm}$.

Different carbon sources such as glucose, dextrose, sucrose, fructose, lactose and maltose were supplemented in the nutrient broth and inoculated with the isolate and were incubated at $35{ }^{\circ} \mathrm{C}$ for $48 \mathrm{hr}$. Different nitrogen sources such as Tryptone, beef extract ammonium chloride, peptone, sodium nitrate and sodium nitrite were supplemented separately to a final concentration of $0.1 \%(\mathrm{w} / \mathrm{v})$ in nutrient broth. Different amino acids such as cysteine, leucine, methionine, tryptophan, histidine, glutamine and proline $(0.5 \%$, final concentration) were dissolved in the nutrient broth. Effect of carbon source, nitrogen source and amino acids ongrowth and pigment production was measured $450 \mathrm{~nm}$.

\section{Antimicrobial activity}

Antimicrobial activity of the pigment extracted by acetone from fermented broth pellet after centrifugation (nutrient agar medium consisting of $1 \%$ (g/l agar),: $5 \%$ (g/l) peptone, $5 \%$ (g/l) NaCl, 10\% (g/l glucose and: $3 \%$ (g/l beef extract andpH 7.0.) was dissolved in DMSO and tested for antimicrobial activity by agar cup plate technique [18] using streptomycin as a positive control and DMSO as a negative control against the test organisms viz. Escherichia coli ATCC 8739, Shigellaflexneri ATCC 12022, Salmonella typhi ATCC 65154 Micrococcus lutea, Staphylococcus aureus ATCC 25923, Pseudomonas aeruginosa ATCC 27853, Vibrio cholera ATCC 15748 and Protius vulgaris. The zone of inhibition was measured after 24 hour incubation [19].

Minimum inhibitory concentrations (MIC) of pigment was performed by agar-cup diffusion method. The crude pigment extract was dissolved in different concentrations ranging from highest concentration of $10,000 \mu \mathrm{g} / \mathrm{ml}$ and then dilution were performed at concentration of $5000 \mu \mathrm{g} / \mathrm{ml}, 4000 \mu \mathrm{g} / \mathrm{ml}, 3500 \mu \mathrm{g} / \mathrm{ml}, 3000 \mu \mathrm{g} / \mathrm{ml}$, $2500 \mu \mathrm{g} / \mathrm{ml}, 2000 \mu \mathrm{g} / \mathrm{ml}, 1500 \mu \mathrm{g} / \mathrm{ml}, 1000 \mu \mathrm{g} / \mathrm{ml}, 750 \mu \mathrm{g} / \mathrm{ml}, 500$ $\mu \mathrm{g} / \mathrm{ml}$ and $250 \mu \mathrm{g} / \mathrm{ml}$. MIC value of extract (IOFP) was determined against eight different human pathogens belonging to both gram positive and gram negative groups such as Escherichia coli ATCC 8739, Shigellaflexneri ATCC 12022, Salmonella typhi Micrococcus lutea, Staphylococcus aureus ATCC 25923, Pseudomonas aeruginosa ATCC 27853, ATCC 65154, Vibrio cholera and Protius vulgaris ATCC 15748. Bacterial suspensions of the test organism were prepared in sterilized Mueller-Hinton broth. Then $50 \mu \mathrm{l}$ of the extract was added to each well. Culture medium without samples and others without microorganisms were used in the testsaspositive and negative control. Plates were incubated at $37{ }^{\circ} \mathrm{C}$ for $20-24 \mathrm{~h}$ and MIC was measured by zone of inhibition [20].

\section{RESULTS AND DISCUSSION}

\section{Isolation and screening of AVP-9 (Kf527823) for fluorescent pigment}

AVP-9 colony was purified by quadrant streak inoculation and screened for fluorescent pigment (fig. 1). Under UV light of longer wave length (fig. 1). Microscopic examination of the isolate showed gram positive rod shaped bacteria that occurred singly or in rosettes [fig. 2]

Biochemical analyses revealed that the fluorescent bacterium avp9(Kf527823) shows the following characteristics based on this, the isolate is belonging to the genus bacillus [table 1].
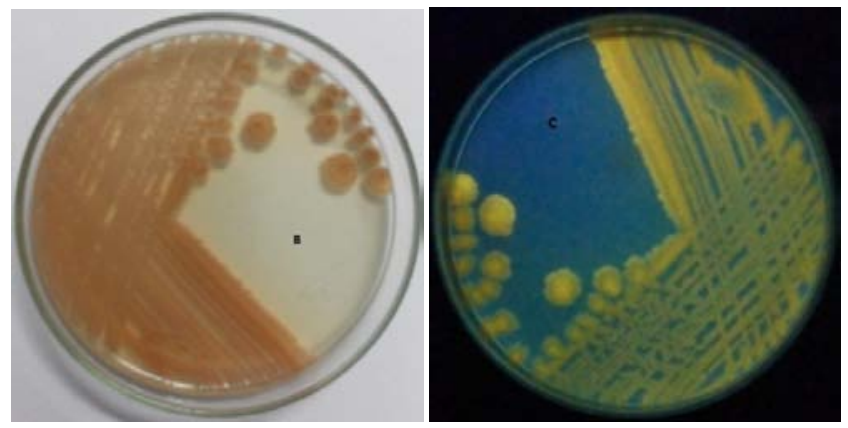

Fig. 1: [a] Purified bacterium observed under daylight (b) Purified bacterium observed u. v daylight

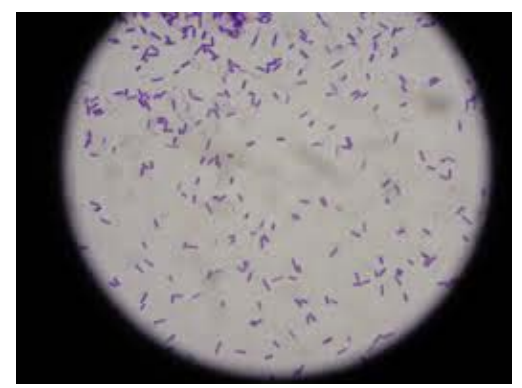

Fig. 2: Microscopic observation of AVP9 
Table 1: Morphological and bio-chemical test results

\begin{tabular}{|c|c|}
\hline \multicolumn{2}{|c|}{ Morphological characteristics } \\
\hline Size & Small \\
\hline Shape & circular \\
\hline Colour & Orange \\
\hline Grams staining & Positive rods \\
\hline Motility & Motile \\
\hline \multicolumn{2}{|l|}{ IMViC tests } \\
\hline Indole & Negative \\
\hline MR & Positive \\
\hline VP & Negative \\
\hline Citrate & Negative \\
\hline \multicolumn{2}{|c|}{ Sugar fermentations } \\
\hline Glucose & $\mathrm{A}^{+} / \mathrm{G}^{-}$ \\
\hline Sucrose & $\mathrm{A}^{+} / \mathrm{G}^{-}$ \\
\hline Fructose & $\mathrm{A}^{+} / \mathrm{G}^{-}$ \\
\hline Maltose & $\mathrm{A}^{+} / \mathrm{G}^{-}$ \\
\hline Lactose & $\mathrm{A}^{-} / \mathrm{G}^{-}$ \\
\hline Arabinose & $\mathrm{A}^{-} / \mathrm{G}^{-}$ \\
\hline Innisitol & $\mathrm{A}^{-} / \mathrm{G}^{-}$ \\
\hline Mannitol & $\mathrm{A}^{+} / \mathrm{G}^{-}$ \\
\hline Sorbitol & $\mathrm{A}^{-} / \mathrm{G}^{-}$ \\
\hline Dulcitol & $\mathrm{A}^{-} / \mathrm{G}^{-}$ \\
\hline \multicolumn{2}{|c|}{ Decarboxylation reactions } \\
\hline \multicolumn{2}{|l|}{ Ornithin } \\
\hline Arginine & Negative \\
\hline Lysine & Positive \\
\hline Creatinine & Positive \\
\hline Malonate & Negative \\
\hline \multicolumn{2}{|c|}{ Enzymatic reactions } \\
\hline Amylase & Negative \\
\hline Urease & Negative \\
\hline Catalase & Positive \\
\hline Oxidase & Positive \\
\hline
\end{tabular}

A-Acid and G-Gas

\section{Optimization of growth and pigment production}

Production of growth and fluorescent Pigment is strongly influenced by physical factors such as temperature, $\mathrm{pH}$, incubation time, inoculum, and media components, especially carbon, nitrogen sources and amino acids. It is important in order. A study of the influence of various physico-chemical parameters was necessaryto find out optimized media for the production of fluorescent Pigment. In present study, initially one parameter was assessed and it was then incorporated at its optimized level in the subsequent experiments using nutrient broth medium.

\section{Effect of temperature}

In this optimization study $4,15,25,30,37$ and $40{ }^{\circ} \mathrm{C}$ was the temperatures selected. There was less fluorescent pigment production was observedat $25^{\circ} \mathrm{C}, 30^{\circ} \mathrm{C} .40^{\circ} \mathrm{C}$ and $37^{\circ} \mathrm{C}$ respectively and no pigment production were observed when incubated at $40^{\circ} \mathrm{C}$ and $15^{\circ} \mathrm{C}$. The maximum 0 . D (0.98) was observed when incubated at $35^{\circ} \mathrm{C}$, and the maximum cell density was observed for $35^{\circ} \mathrm{C}$ and no growth was observed at $40^{\circ} \mathrm{C}$ (fig. 3).

\section{Effect of incubation time}

Optimization of fluorescent Pigment production was initiated by incubating the selected strain at different time durations of $12 \mathrm{~h}$ equal intervals. The selected isolate showed maximum growth 1.71 at $72 \mathrm{~h}$ and less 0.51 at $12 \mathrm{~h}$. Maximum fluorescent Pigment production 1.48 at $48 \mathrm{~h}$ and less 0.21 at $12 \mathrm{~h}$ showing that, further increase in temperature reduces the pigment production (fig. 4)

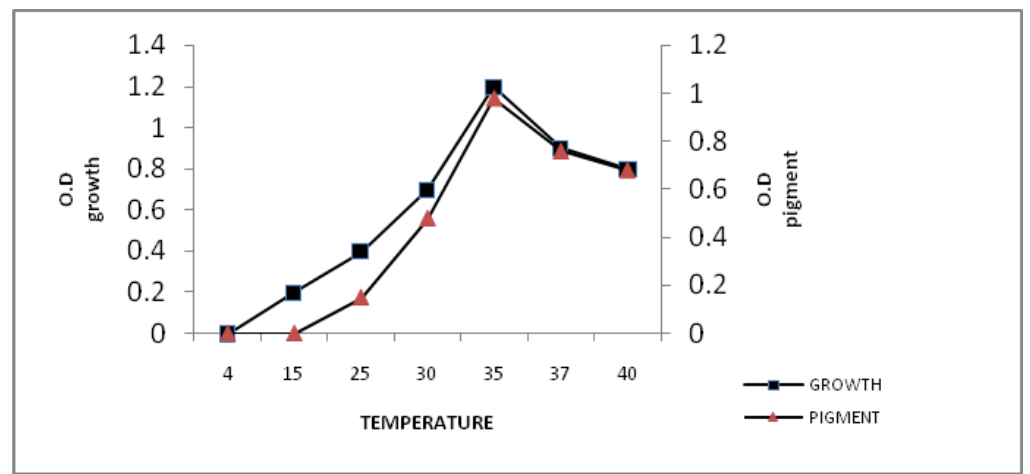

Fig. 3: Effect of temperature on production of Growth and fluorescent Pigment by avp-9 showing maximum growth and pigment production at $35^{\circ} \mathrm{C}$ and no growth at $4^{\circ} \mathrm{C}$ no pigment production at both 4 and $15{ }^{\circ} \mathrm{C}$ 


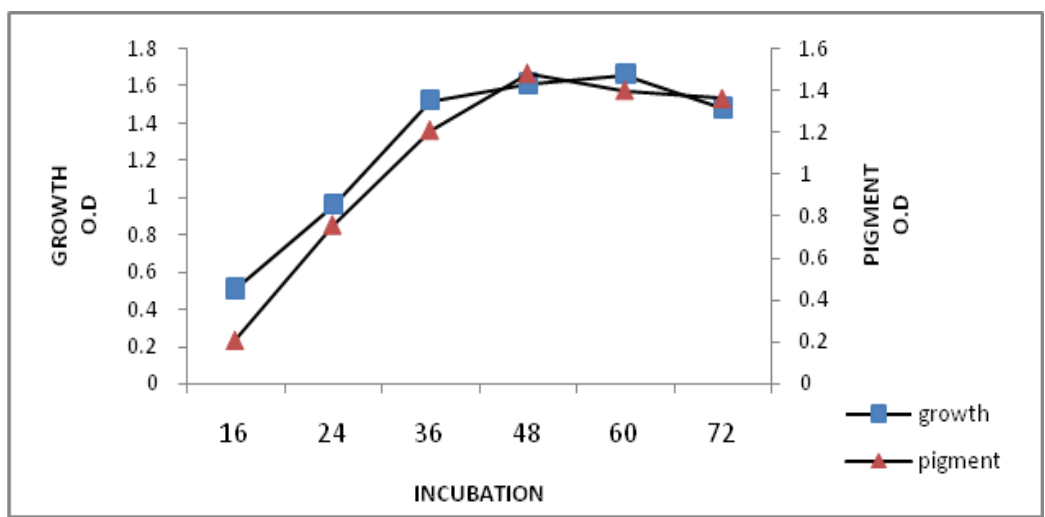

Fig. 4: Effect of Incubation time on production of fluorescent pigment by avp-9 (Nutrient broth; temperature $35^{\circ} \mathrm{C}$; incubation period $48 \mathrm{~h}$; results are mean of independent experiments $\pm S D$ and are expressed as 0 . D at $450 \mathrm{~nm}$

\section{Effect of inoculums size}

An investigation for further increase in growth and fluorescent Pigment production, the effect of various inoculum sizes was studied. To evaluate the effect of inoculum size, varied cell concentrations $(0.5,1.0$ and $1.5 \%)$ were added to separate flasks and then carried out as described in materials and methods. Growth and fl. Pigment production varied with inoculum level and showed a parabolic nature in the studied range (fig. 3 ). The maximum growth was at $1.5 \%$ inoculum, and fluorescent Pigment production was maximum at $1.0 \%$ and further decreased in increased inoculum concentration fig. 5 .

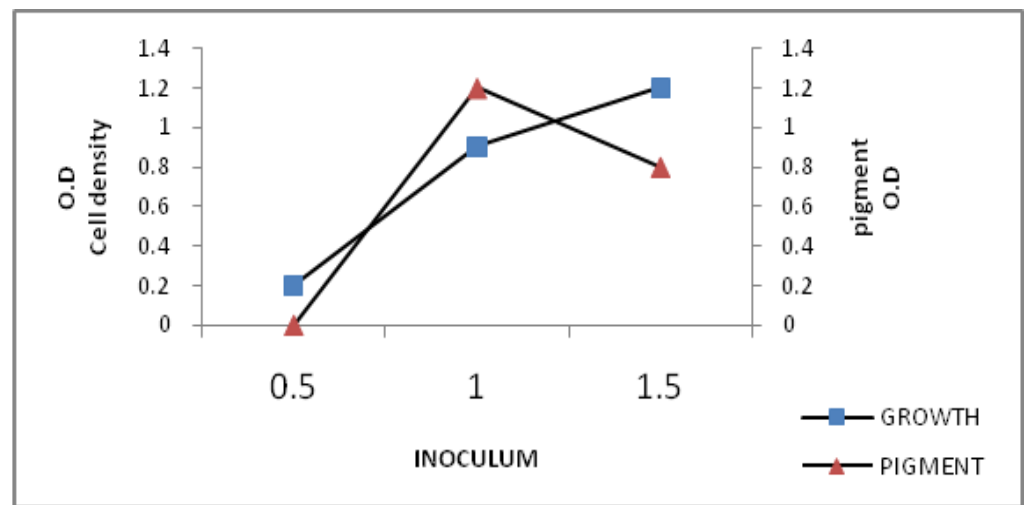

Fig. 5: Effect of inoculum size (1\%) on production of fl. Pigment by AVP-9 (Nutrient broth; inoculum $1 \%$; temperature $35^{\circ} \mathrm{C}$; incubation period $48 \mathrm{~h}$; results are mean of independent experiments $\pm S D$ and are expressed as 0 . D at $450 \mathrm{~nm}$

\section{Effect of pH}

Selected potential bacterial strain were subjected to various concentrations of $\mathrm{pH}$ ranging from 3.0 to 10.0 were taken for the study of an interval of $\mathrm{pH}$ 1.0. Maximum growth at 1.30 at ph 7.0 and decreased further increases the $\mathrm{pH}$ beyond 7.0. No growth was registered at $\mathrm{ph}$ range of 4-5. Maximum pigment 0.96 and reduced further increases the pH beyond 7.0. No pigment was recorded at ph range of 4-5. fig. 6

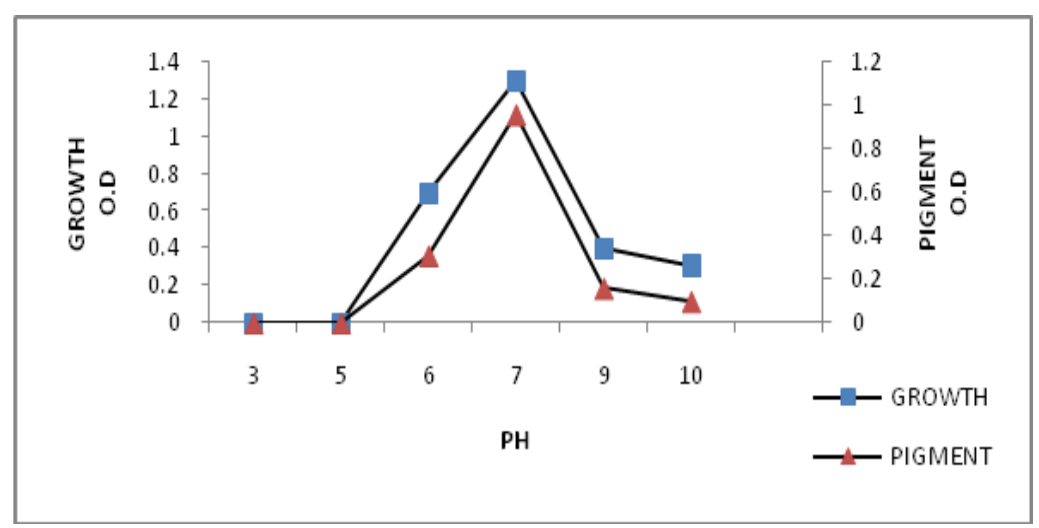

Fig. 6: Effect of $\mathrm{pH}$ on production of growth and pigment by avp-9(Nutrient broth; inoculum $1 \%$; temperature $35^{\circ} \mathrm{C}$; incubation period 48 $h$; and ph 7.0. results are mean of independent experiments $\pm S D$ and are expressed as 0 . $D$ at 450 


\section{Role of different carbon sources}

Effect of glucose, dextrose, sucrose, fructose, lactose and maltose as a carbon source has largely influenced the selected strain for the fluorescent Pigment production. Maximum Growth was observed 1.7 for glucose and less 1.12 for dextrose. Maximum fluorescent Pigment production 1.51in glucose and no pigment were produced in the remaining sugars. In the present study, the maximum fl. Pigment was observed in the medium containing glucose as the carbon source. fig. 7.

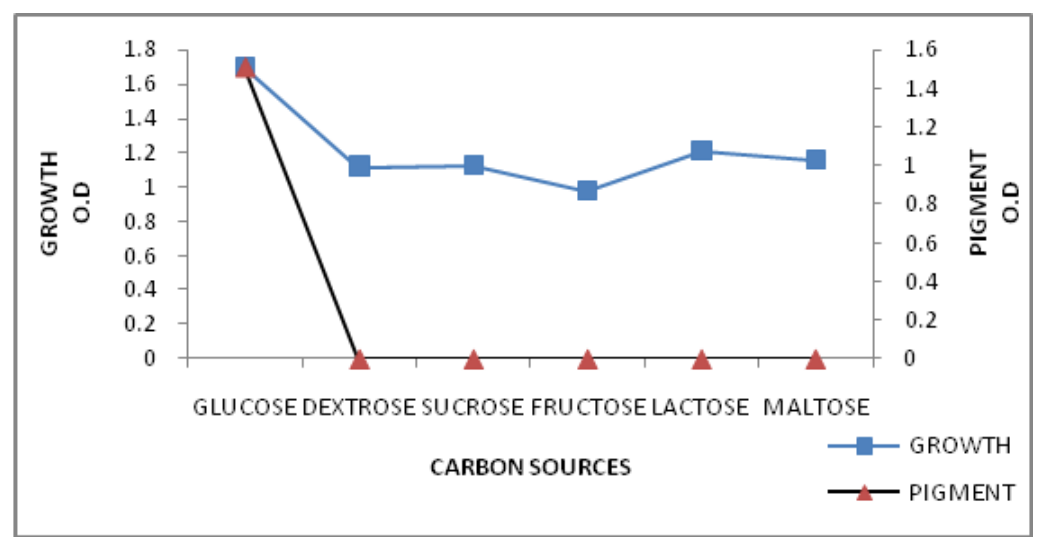

Fig. 7: Effect of carbon sources on production growth and fl. Pigment by AVP-9(Nutrient broth; inoculums $1 \%$; temperature $35{ }^{\circ} \mathrm{C}$; incubation period 48h; PH at 7.0, 1\% glucose. results are mean of independent experiments \pm SD and are expressed as $0 . D$ at $450 \mathrm{~nm}$

\section{Effect of various concentrations of glucose}

Glucose concentration of $1.5 \%$ was optimum for cell growth and optimum pigmentation 1.2 is at the concentration of $1.0 \%$. [fig. 8]. Glucose, usually an excellent carbon source for growth, interferes with the synthesis of many secondary metabolites. Because of parallels with the well-known suppression by glucose of catabolic enzymes that use less-preferred substrate, this has been referred to as 'catabolite repression'. In many secondary metabolite pathways, the enzymes subject to control by the carbon source are known.

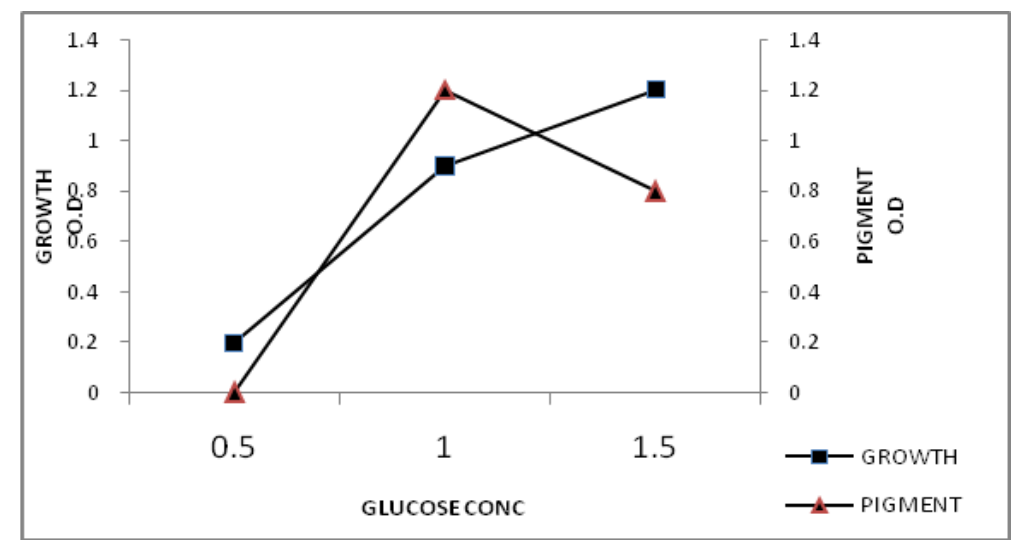

Fig. 8: Effect of various glucose concentration on growth and pigment by avp-9 (Nutrient broth; inoculum $1 \%$; temperature $35^{\circ} \mathrm{C}$; incubation period $48 \mathrm{~h}$, ph 7.0; carbon glucose

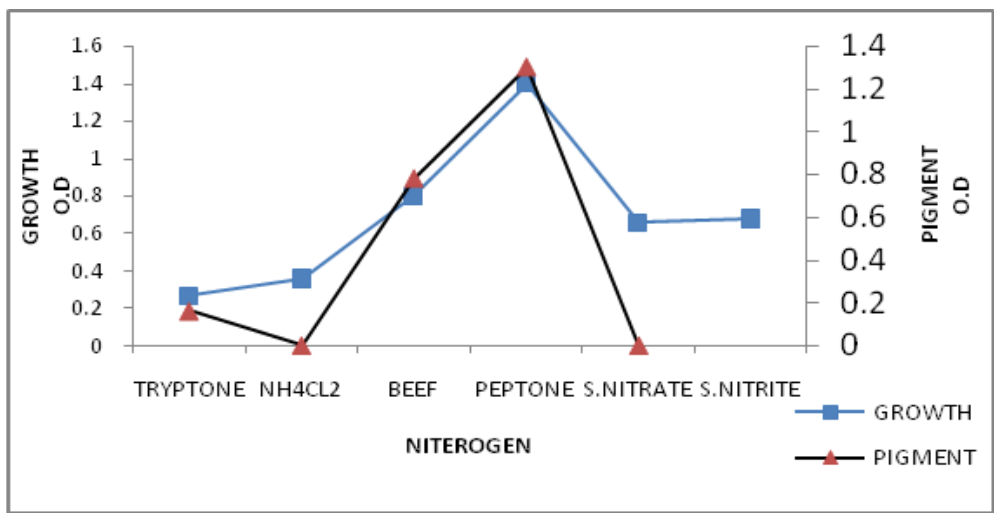

Fig. 9: Effect of Nitrogen sources on production of growth and pigment by avp-9 (Nutrient broth; inoculum $1 \%$; temperature $35{ }^{\circ} \mathrm{C}$; incubation period $48 \mathrm{~h}$; ph 7.0; carbon glucose; nitrogen peptone; results are mean of independent experiments \pm SD and are expressed as $0 . D$ in $\mathrm{nm}$ 


\section{Role of different nitrogen sources}

Different nitrogen sources viz., Tryptone, ammonium chloride, beef extract, peptone, sodium nitrate, and sodium nitrite. Nitrogen source is critical to the organism for growth and pigment production. Peptone supported maximum growth and pigment production. Maximum growth observed at $1 \%$ peptone and minimum 0.27 is at $1 \%$ Tryptone. Maximum pigment was produced 1.30 at $1 \%$ peptone and less 0.16 at $1 \%$ Tryptone were as no pigment was found in sodium nitrate, sodium nitrite and ammonium chloride [fig. 9]. Various nitrogen sources studied by for the fluorescent pigment production. The present study revealed that the growth and fluorescent pigment production was very low when incorporated with various inorganic nitrates. Skilled production was noticed in the case of peptone supplemented medium. This may be explained by containing of amino acids, vitamins and coenzyme to promote the production of growth and fluorescent pigment.

\section{Effect of different amino acids}

In order to examine the effect of different amino acids sources, leucine, proline, methionine, histidine, glutamine and cysteine were tested. Maximum growth 1.12 at $0.5 \%$ methionine and less 0.41 at $0.5 \%$ cysteine. Maximum pigment 1.60 at $0.5 \%$ methionine and less cysteine 0.36 was registered. (fig. 10).

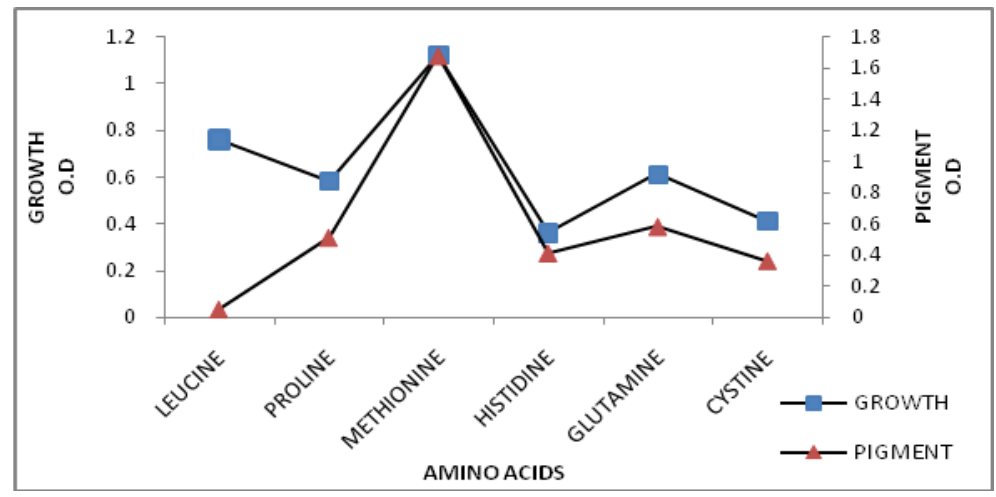

Fig. 10: Effect of amino acids on production growth and fl. pigment by avp-9 (Nutrient broth; inoculum $1 \%$; temperature $35{ }^{\circ} \mathrm{C}$; incubation period $48 \mathrm{~h}$; ph 7.0; carbon glucose; nitrogen peptone; amino acids methionine; results are mean of independent experiments \pm SD and are expressed as O.D. in $450 \mathrm{~nm}$

\section{Effect of different media on fl. pigment production}

Among the Medias tested for fluorescent Pigment production, viz., modified nutrient broth, lactose broth, Tryptone soya broth and peptone water, the isolate showed maximum 0 . D1.17 at $450 \mathrm{~nm}$, compared to 1.01 in peptone water, 0.88 in Tryptone soya broth and no pigment production were noticed lactose broth. Cell density of modified nutrient broth showed 1.48, 0.98 in Tryptone soya broth, 0.61 in peptone water and least cell growth 0.40 noticed in lactose broth. Comparing the results, modified nutrient broth showed highest fl. Pigment production. Hence, the modified nutrient broth has been chosen for further studies (fig. 11) [21].

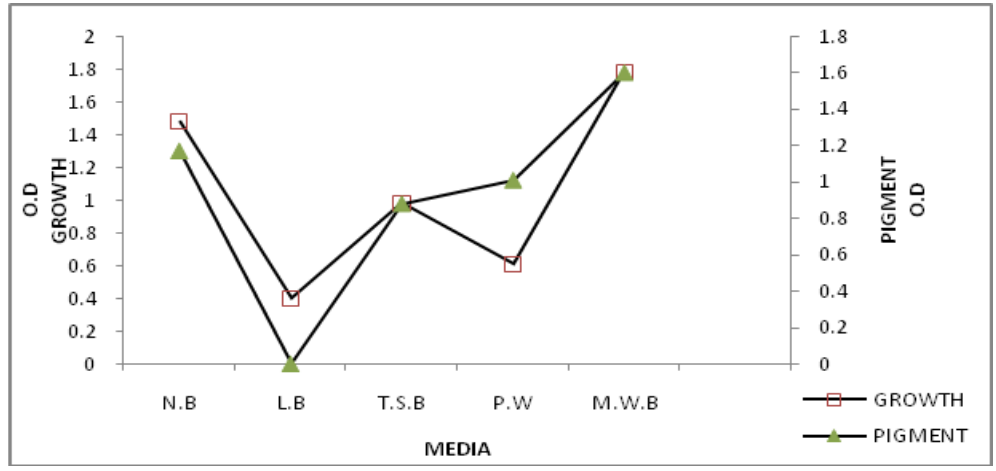

Fig. 11: Effect of various medias on production of growth and fl. Pigment by avp-9, showing maximum growth and pigment production on modified nutrient broth were as fever growth and nopigment production on lactose broth

\section{Extraction of pigment}

Different solvents such as acetone, ethyl acetate, butanol, hexane and chloroform were utilized to extract the pigment from the centrifuged pellet. Acetone has been found to be the most suitable solvent to extract the pigment. The detail procedure for extraction and fractionation of the pigment is stated as in materials and methods fig. [12].

Thin layer chromatography of the crude pigment was extracted with acetone and purified using silica gel as absorbent and solvent system chloroform: ethyl acetate (3:1), gives one bright orange spot of Rf value 0.55 which fluoresced orange yellow under light. [fig. 12A]. and named as intracellular fluorescent pigment (IOFP).

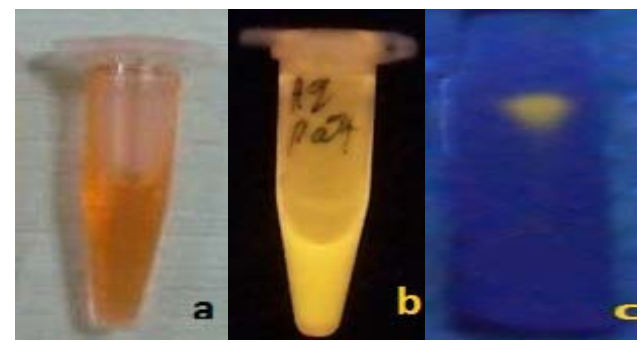

Fig. 12: [a] Bright orange pigment extracted with acetone, [b] pigment fluoresced bright, [c] Yellow orange under long wavelength of $u$. $v$ light 
The UV-Visible absorption of sample IOFP gives peak at $493 \mathrm{~nm}$ which indicate the presence of carotenoid pigment. Further studies are required to analyze the carotenoid sample (fig. 12b)

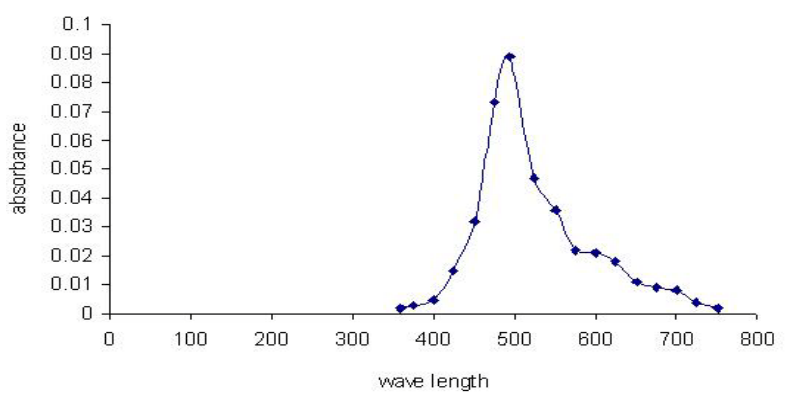

Fig. 12B: Absorption spectra of purified fluorescent pigment10FP of AVP9 from $350 \mathrm{~nm}$ to $760 \mathrm{~nm}$ showing absorption maxima at $493 \mathrm{~nm}$

\begin{abstract}
Antimicrobial activity
Dried pigment fraction IOFP obtained by fractionation of the crude pigment was dissolved in DMSO $(1000 \mu \mathrm{g} / \mathrm{ml})$ and tested for antimicrobial activity by agar cup plate technique [17] against the test organisms using DMSO as a control. It was observed fraction IOFP show antibacterial activity against E. coli, Shigellaflexneri, Micrococcus. lutea,Staphylococcus aureus, Pseudomonas aeruginosa, Salmonella typhi, Vibrio cholerae, and Protius vulgaris. [table 2]
\end{abstract}

\section{MIC of the pigments}

OMIC value was determined for IOFP which showed better antibacterial activity. The MIC value of the pigment against Grampositive and Gram-negative bacteria ranged from 500 to 2,000 $\mu \mathrm{g} / \mathrm{ml}$. Lowest MIC value $(500 \mu \mathrm{g} / \mathrm{ml})$ was found against only gram negative bacteria. MIC value was much higher than control antibiotic, Streptomycin $(30 \mu \mathrm{g} / \mathrm{ml})$. Considering the impurities and complex composition of the extracted pigment. MIC value against the pathogens included in this study was promising though Streptomycin had much lower MIC value [table 3].

Table 2: Antimicrobial property of the fraction IOFP

\begin{tabular}{|c|c|c|c|}
\hline Pathogens & $\begin{array}{l}\text { Zone of inhibition(mm) } \\
\text { IOFP } 1000(\mu \mathrm{g} / \mathrm{ml})\end{array}$ & $\begin{array}{l}\text { Streptomycin } 1000 \\
(\mu \mathrm{g} / \mathrm{ml}) \text { positive control }\end{array}$ & $\begin{array}{l}\text { DMSO } 1000(\mu \mathrm{g} / \mathrm{ml}) \\
\text { positive control }\end{array}$ \\
\hline E. coli & 45 & 48 & 00 \\
\hline Shigella flexneri & 35 & 52 & 00 \\
\hline Micrococcus. lutea & 42 & 47 & 00 \\
\hline Staphylococcus aureus & 50 & 34 & 00 \\
\hline Pseudomonas aeruginosa & 23 & 40 & 00 \\
\hline Salmonella typhi & 36 & 39 & 00 \\
\hline Vibrio cholerae & 33 & 30 & 00 \\
\hline Protius vulgaris & 26 & 35 & 00 \\
\hline
\end{tabular}

A Excluding the diameter of the well which is $6 \mathrm{~mm}$.

Table 3: Minimum inhibitory concentration of the fractions IOFP

\begin{tabular}{llc}
\hline Pathogens & Mic value $(\boldsymbol{\mu g} / \mathbf{m l}) \mathbf{I O F P} \mathbf{1 0 0 0}(\boldsymbol{\mu g} / \mathbf{m l})$ & Streptomycin $\mathbf{1 0 0 0}(\boldsymbol{\mu g} / \mathbf{m l})$ \\
\hline E. coli & 500 & 10 \\
Shigella flexneri & 2000 & 10 \\
Micrococcus. lutea & 2500 & 15 \\
Staphylococcus aureus & 1500 & 10 \\
Pseudomonas aeruginosa & 1000 & 20 \\
Salmonella typhi & 1500 & 10 \\
Vibrio cholerae & 1500 & 25 \\
Protius vulgaris & 1000 & 10 \\
\hline
\end{tabular}

\section{CONCLUSION}

In the present study, distinctive pigmentation of fluorescent bacterium Bacillus endophyticus AVP-9(Kf527823) is due to the presence of carotenoid group, which renders them to be tolerant to extreme light conditions and radiation. Based on the morphological and biochemical properties, the isolated bacterium was identified as bacillus spp. The effects of important parameters such as temperature, $\mathrm{pH}$, and carbon source on growth and pigmentation were studied and optimum range of each parameter was achieved. The optimum condition for growth and pigmentation in modified nutrient broth was considered to be $\mathrm{C}, 5 \mathrm{pH} 7.0$, with $1.0 \%$ of glucose. The organism was mass multiplied these optimum conditions and pigment was extracted solvent extraction method as acetone serves as capable solvent which gives distinctive band on preparative TLC plate with $R_{f}$ value of 0.55 . The sample was measured in U. V/Vis Spectrophotometry and found to be maximum at $493 \mathrm{~nm}$, which indicate the presence of carotenoid pigment, which had ability of having anti-bacterial activity. Scope for further research would be the purification and characterization of carotenoid pigments obtained from AVP9.

\section{ACKNOWLEDGEMENT}

I sciencerly thankful to Mr. S. V. BalaMurali Krishna and K. Vamsi Krishna managing partners of Wisdom Associates Guntur,A. P,
INDIA. For their unconditional support and financial assistance and to Miss P. DhanyaBharathi and A. Rama Lakshmi for providing valuble chemicals.

\section{CONFLICT OF INTERESTS}

Declare none

\section{REFERENCES}

1. Hackl E, Boltenstern S, Bodrossy L, Sessitsch A. Comparison of diversities and compositions of bacterial populations inhabiting natural forest soils. Appl Env Microbiol 2004;7:5057-65.

2. Carbonell GV, DallaColleta HHM, Yano T, Levy CE, Fonseca BAI. Clinical relevance and virulence factors of pigmented Serratia marcescens. FEMS Immunol Medical Microbiol 2000;28:143-9.

3. Selvameenal L, Radhakrishnan M, Balagurunathan R. Antibiotic pigment from desert soil actinomycetes; biological activity, purification and chemical screening. Indian J Pharma Sci 2009;71:499-504.

4. Mekhael R, Yousif SY. The role of red pigment produced by Serratiamarcescens antibacterial and plasmid curing agent. J Duhok Univ 2009;12:268-74.

5. Yokoyama A, Miki W. Composition and presumed biosynthetic pathway of carotenoids in the astaxanthin-producing 
bacterium Agrobacterium aurantiacum. FEMS Microbiol Lett 1955; 128:139-44.

6. Giri AV, Anandkumar N, Muthukumaran G, Pennathur G. A novel medium for the enhanced cell growth and production of prodigiosin from Serratiamarcescens isolated from soil. BMC Microbiol 2004;4:2-14.

7. Dufosse L. Pigments, Microbial. Encyclopedia Microbiol 2009;4:457-71.

8. Goodwin KD, Varner RK, Crill PM, Oremland RS. Consumption of tropospheric levels of methyl bromide by C1 compoundutilizing bacteria and comparison to saturation kinetics. Appl Environ Microbiol 2001;67:5437-43.

9. Benemann JR. Microalgae aquaculture feeds. J Appl Phycol 1992;4:233-45.

10. Astorg P. Food carotenoid and cancer prevention: an overview of current research. Trends Food Sci Technol 1997;8:406-13.

11. Green PN, Bousfield IJ. A taxonomic study of some gramnegative facultatively methyl trophicbacteria. Gen Microbiol 1982;128:623-38.

12. Cross T. Growth and examination of actinomycetes-some guidelines. In: Bergey's manual of systematic bacteriology. ST Williams, ME Sharpe, JP Holt. Eds. Vol. 4. Baltimore: Williams and Wilkins; 1989. p. 2340-3.

13. Stahl E. Apparatus and general techniques in thin layer chromatography (A Laboratory Handbook. 2nd ed. New York: Springer; 1969.

14. Jyothilaxmi, Palanichamy V, Narayanareddy N, Rajsekaran C, Nancy Veenakumari D, Bhaskar Mitra. Standardization of cultivation parameters for the extraction of carotenoid from pink pigmented facultative methylotrophic (ppm) bacteria; 2012.

15. Cang S, Sanada M, Johdo O, Ohta S, Nagamatsu Y, Yoshimoto A. High production of prodigiosin by Serratiamarcescens grown on ethanol. Biotechnol Lett 2000;22:1761-5.

16. Gallo M, Katz E. Regulation of secondary metabolite biosynthesis: catabolite repression of phenoxazinone synthase and actinomycin formation by glucose. J Bacteriol 1972;109:659-67.

17. Martin JF, Demain AL. Control of antibiotic biosynthesis. Microbiol Rev 1980;44:230-51.

18. Collins CH, Lyne PM. Microbiological methods. 3rd ed. Baltimore: University Park Press; 1970.

19. Difco manual of dehydrated culture media and reagents for microbiological and clinical laboratory procedures, Difco Laboratories Incorporated, Detroit 1, Michigan; 1953.

20. Saha A, Rahman MS. Antimicrobial activity of crude extract from Calycopterisfloribunsa. Bang J Microbiol 2008;25:137-9.

21. Andrewmagyarosy A, ZHO Jonathan, Henry Rapoport, Jay Keasling. Chloroxanthomycin, a fluorescent, chlorinated pentacyclic pyrene from a Bacillus sp. J Appl Environ Microbiol 2002;68:4095-101.

\section{How to cite this article}

- Mantri Sai Ram, Nokku Pradeep Kumar, CVS Bhaskar, Amrutha V Audipudi. Optimization and charecterization ofintracellular orange fluorescent pigment from bacillus endophyticus (AVP9(Kf527823). Int J Curr Pharm Res 2017;9(5):67-74. 